Running head: INHIBITORY CONTROL TRAINING AND SMOKING

\title{
A Randomised Controlled Trial of Inhibitory Control Training for Smoking Cessation and Reduction
}

Date submitted: December $4^{\text {th }}, 2018$ 


\begin{abstract}
Objective: The high rates of illness and mortality associated with cigarette smoking necessitate the development of novel reduction and cessation treatments. Inhibitory control training (ICT) has recently emerged as a potentially efficacious intervention to reduce the consumption of alcohol and unhealthy food. This randomised controlled trial was the first to investigate the effect of internetdelivered ICT on cigarette consumption in a community sample of heavy smokers. Method: Onehundred and seven adult smokers (mean age $=46.15,57$ female), who smoked a minimum of 10 cigarettes per day, and met criteria for a moderate or severe Tobacco Use Disorder, were recruited for the present study. Participants were randomly allocated to receive Go/No-Go training in which either smoking stimuli (intervention) or non-smoking stimuli (control) were paired with No-Go signals and were instructed to complete one training session per day over a two-week period. This trial was preregistered with the Australian and New Zealand Clinical Trials Registry (Trial ID:
\end{abstract}

ACTRN12617000252314). Results: We found no significant differences between conditions on percent days abstinent or daily cigarette consumption, although there was a significant decrease in daily cigarette consumption across both conditions. Further, we found no significant moderating effects of impulsivity on the relationship between cigarette consumption and the two tasks.

Conclusions: Although participants in both conditions reduced their daily cigarette consumption, the intervention task was no more successful than the control task in achieving cigarette abstinence or reduction.

Keywords: smoking; inhibitory control; impulsivity; cognitive training; e-health.

\title{
Public health significance statement
}

Findings from this randomised controlled trial suggest that smoking-specific inhibitory control training (ICT) does not appear to help adult smokers cease or reduce cigarette smoking compared to an active control task. 


\section{INHIBITORY CONTROL TRAINING AND SMOKING}

\section{Introduction}

Cigarette smoking is one of the leading preventable causes of illness and premature death worldwide (World Health Organisation [WHO], 2015). In 2015, over 6 million people died globally as a result of smoking and, if current mortality trends persist, this number will exceed eight million by the year 2030 (Forouzanfar et al., 2016; WHO, 2011). Despite a variety of effective behavioural and pharmacological treatments (Cahill, Stevens, Perera, \& Lancaster, 2013; Lancaster \& Stead, 2017; Stead \& Lancaster, 2012), relapse to smoking remains the most likely outcome (Hughes, Peters, \& Naud, 2008; Piasecki, 2006), highlighting the need for novel and innovative smoking reduction and cessation treatments.

In recent years, inhibitory control training (ICT) has emerged as a potentially efficacious intervention to reduce addictive and unhealthy behaviours, such as the consumption of alcohol or unhealthy food (Allom, Mullan, \& Hagger, 2015; Jones et al., 2016). Using modified Go/No-Go (GNG) or Stop-Signal tasks (SST), ICT requires participants to establish prepotent motor responses towards neutral stimuli (e.g., clothes), while, on a minority of trials, pairs cue-specific stimuli (e.g., unhealthy food/alcohol) with stop or No-Go signals (Jones et al., 2016). It has been proposed that the pairing of cue-specific stimuli with stop/No-Go cues leads to the automatisation of inhibition towards these stimuli (Logan, 1988; Verbruggen, Best, Bowditch, Stevens, \& McLaren, 2014; Verbruggen \& Logan, 2008a) or, alternatively, results in a reduced approach tendency towards these stimuli via devaluation (Veling, Holland, \& van Knippenberg, 2008).

ICT interventions were developed from extensive research demonstrating that impaired inhibitory control, defined as the ability to stop, or withhold an unwanted or inappropriate response (Logan, Cowan, \& Davis, 1984), is an important component in the development and maintenance of addictive and other health-related behaviours (Goldstein \& Volkow, 2002; Hall, 2012; Luijten et al., 2014; Perry \& Carroll, 2008; Smith, Mattick, Jamadar, \& Iredale, 2014). Indeed, for smokers, research has shown that deficits in inhibitory control are positively associated with cigarette consumption (Billieux et al., 2010; Spinella, 2002), relapse following a cessation attempt (Krishnan- 


\section{INHIBITORY CONTROL TRAINING AND SMOKING}

Sarin et al., 2007; Powell, Dawkins, West, Powell, \& Pickering, 2010) and nicotine dependence (Billieux et al., 2010; Glass et al., 2009). Further, a recent meta-analysis compared the inhibitory control capacities of substance users with controls and found that cigarette smokers exhibited significant inhibitory control deficits (via GNG tasks; Smith et al., 2014). Consequently, 'training' this potentially modifiable risk-factor may lead to improved reduction and cessation outcomes.

The effectiveness of ICT in reducing the consumption of alcohol (Bowley et al., 2013; Houben, Havermans, Nederkoorn, \& Jansen, 2012; Houben, Nederkoorn, Wiers, \& Jansen, 2011; Jones \& Field, 2013) and unhealthy food (Houben, 2011; Houben \& Jansen, 2011, 2015; Veling, Aarts, \& Papies, 2011; Veling, Aarts, \& Stroebe, 2013) and, more recently, smoking (Adams, Mokrysz, Attwood, \& Munafò, 2017), has primarily been examined within a laboratory setting. For instance, Houben et al. (2011) embedded cue-specific (i.e., alcohol-related) and neutral pictures (i.e., water) into a GNG task and randomly allocated participants to one of two conditions: a No-Go condition, which consistently paired cue-specific stimuli with a stopping response, and a Go condition, which consistently paired cue-specific stimuli with the requirement to respond. Following a single ICT session within the laboratory, participants in the No-Go condition consumed significantly less self-reported alcohol in the week following the session compared with pre-intervention alcohol consumption. Similar findings were reported by Jones and Field (2013). In their study, following a single ICT session which utilised an alcohol-paired SST, social drinkers were found to consume significantly less alcohol in a subsequent taste test. Recently, Adams et al. (2017) conducted a laboratory-based ICT program with smokers and examined the effect of a single session smokingspecific GNG training task on cigarette consumption in comparison to a control GNG training task. They found no significant differences between groups on post-training cigarette consumption seven days later; however, participants in their study were not required to have an intention to quit smoking and, their control task paired smoking-related stimuli with No-Go signals on 50\% of trials, which may have had a reduction effect on cigarette consumption. Therefore, further research is warranted to examine whether these factors contributed to their null findings. 


\section{INHIBITORY CONTROL TRAINING AND SMOKING}

Importantly, ICT has been found to be effective when delivered outside of the laboratory and in real-world settings (Allom \& Mullan, 2015; Lawrence et al., 2015; Veling, van Koningsbruggen, Aarts, \& Stroebe, 2014). For example, Lawrence et al. (2015) implemented an internet-delivered ICT program for 83 mostly overweight and obese adults. Participants were randomly allocated to receive four, 10-minute training sessions in which either high calorie food (i.e., intervention) or non-food stimuli (i.e., control) were paired with No-Go signals. At one-week follow-up, participants in the intervention condition consumed less food and showed significant weight loss and had decreased positive evaluations of high calorie foods compared to the control condition. Furthermore, at six months, participants in the intervention condition displayed significantly higher average self-reported weight loss compared to the control condition $(d=.47)$, suggesting that cue-specific ICT can yield sustained effects. In contrast, Jones et al. (2018) recently examined the effectiveness of an internetdelivered ICT program in reducing alcohol consumption in a community sample of 246 problem drinkers. In their study, participants were randomly allocated to one of three training conditions (cuespecific GNG, cue-specific SST, general SST) or a control condition (self-monitoring only) and were required to complete a maximum of 14 ICT sessions over a four-week period. While all conditions reported reductions in alcohol consumption, they found no significant differences between conditions on any measures of alcohol consumption. The authors noted that prior to commencing ICT, participants were required to complete an online alcohol intervention (Linke, Brown, \& Wallace, 2004) in order to increase their motivation to reduce alcohol consumption, which may have masked the reduction effects of ICT. In conclusion, there is mixed evidence regarding the effectiveness of ICT in real-world settings and interestingly, no online study has examined whether it might be effective in assisting individuals to reduce or quit smoking. Given the accessibility and affordability potential of an effective internet-based ICT smoking intervention, such a study is worthy of investigation.

Since ICT is a relatively new intervention, it is also important to investigate whether any individual differences influence the effectiveness of training. That is, whom does it work best for? To date, this has received minimal attention. However, given that ICT purports to target impulses evoked 


\section{INHIBITORY CONTROL TRAINING AND SMOKING}

by the exposure to cue-specific stimuli (Veling et al., 2008; Verbruggen \& Logan, 2008a), it follows that individuals with low inhibitory control, and indeed more broadly, high trait impulsivity, would likely benefit the most. To date, only one study (Houben, 2011) has examined the moderating role of inhibitory control on the effectiveness of ICT. Specifically, Houben (2011) assessed 29 participants' baseline inhibitory control using the SST and then subsequently measured their unhealthy food consumption following a single ICT session. It was found that ICT was more effective at reducing unhealthy food consumption for participants with low baseline inhibitory control abilities compared to high levels of baseline inhibitory control. Other studies have used indicators of impulsivity such as body mass index or dietary restraint and found that ICT was more effective for individuals who possessed stronger impulses towards foods (Lawrence, Verbruggen, Morrison, Adams, \& Chambers, 2015; Veling et al., 2011; Veling et al., 2013; Veling et al., 2014). As of yet, no studies have examined whether trait impulsivity moderates the effectiveness of ICT; however, given the extensive literature demonstrating that it shares robust positive associations with cigarette consumption and relapse (Bloom, Matsko, \& Cimino, 2013; Bos, Hayden, Lum, \& Staiger, 2019; Kale, Stautz, \& Cooper, 2018), we also expect ICT to be more effective for participants with high trait impulsivity. Overall, the primary aim of the present study was to investigate the effectiveness of ICT on smoking in a community sample of heavy smokers. We used a GNG paradigm as two recent metaanalyses (Allom et al., 2015; Jones et al., 2016) demonstrated that the magnitude of the effect of ICT on alcohol and unhealthy food consumption were in the medium range for GNG tasks, whereas for SSTs, they were in the small range (Cohen, 1992). Thus, based on the work of Lawrence et al. (2015), we examined the effect of an online smoking-specific GNG training task on cigarette consumption in comparison to a non-smoking GNG training task. We chose a non-smoking GNG task as our control as it was not expected to affect smoking behaviour (Guerrieri, Nederkoorn, \& Jansen, 2012; Lawrence, Verbruggen, Morrison, Adams, \& Chambers, 2015; Oomen, Grol, Spronk, Booth, \& Fox, 2018) and, it ensured that we controlled for the difficulty and demands of the intervention task so as to maximise participant blinding. As such, our control can be considered 'active'. This is the first study 


\section{INHIBITORY CONTROL TRAINING AND SMOKING}

to investigate ICT on smoking outside of the laboratory and in doing so, adds to the important body of literature testing the effectiveness of ICT in reducing unhealthy behaviours. If shown to be effective, internet-delivered ICT could be an accessible, convenient and cost-efficient treatment for smokers with the potential of reducing smoking-related mortality rates.

Our pre-registered hypotheses were:

1) Participants who received smoking-specific ICT would report higher abstinent rates compared to participants in the active control condition at post-intervention and one-month and three-months follow-up.

2) Participants who received smoking-specific ICT would report lower daily cigarette consumption compared to participants in the active control condition at post-intervention and one-month and three-months follow-up.

3) Impulsivity would moderate the relationship between smoking-specific ICT and cigarette consumption. Specifically, participants with low inhibitory control and/or high trait impulsivity would report greater reductions in cigarette consumption following smokingspecific ICT compared to participants with high inhibitory control and/or low trait impulsivity at post-intervention and one-month and three-months follow-up.

We also conducted three exploratory analyses that were not pre-registered which examined whether the standard demographic variables of gender and age, or training dose (i.e., the number of sessions completed) moderated the relationship between condition and cigarette consumption. This double blind randomised controlled trial (RCT) was pre-registered with the Australian and New Zealand Clinical Trials Registry and was implemented in accordance with JARS guidelines (Appelbaum et al., 2018).

\section{Method}

\section{Design}

We conducted a double-blind RCT comparing the effect of an intervention task to a control task in a group of heavy smokers who wished to quit. The intervention task was a smoking version of 


\section{INHIBITORY CONTROL TRAINING AND SMOKING}

the food GNG task used in Lawrence et al. (2015) and the control task is similar to the non-food GNG task in Lawrence et al. (2015), with No-Go training to household items. A permuted block randomisation procedure was utilised (Altman \& Schulz, 2001) whereby participants were automatically allocated to the intervention or control condition via the computer through the use of a randomly generated number. The permuted blocks were organised in groups of ten, the details of which were not known by researchers involved with the administration of the trial. The trial was registered prior to data collection (Trial ID: ACTRN12617000252314) and remained as per initial registration. An accompanying protocol paper is available in open access (Staiger et al., 2018). This study was approved by the Deakin University Human Research Ethics Committee (Project ID: 2015298).

\section{Participants}

A total of 107 (57 female) adult smokers with a mean age of 46.15 years $(S D=9.38$, range $=$ $20-60)$ took part in the present study (see Table 1). The sample size was smaller than intended (150; Staiger et al., 2018); however, we terminated recruitment early as attrition rates were substantially lower than expected and we had reached the necessary sample size for adequate statistical power. On average, participants smoked 18.79 cigarettes per day $(S D=6.93$, range $=10-44)$ and all met criteria for a moderate $(n=41,38 \%)$ or severe $(n=66,72 \%)$ Tobacco Use Disorder according to the Diagnostic and Statistical Manual of Mental Disorders, $5^{\text {th }}$ edition (DSM-5; American Psychiatric Association [APA], 2013).

\section{[Insert Table 1]}

Participants were recruited via traditional media (radio, newspaper and television), social media (Facebook) and leaflets within Deakin University. Participants were included if they met the following criteria: 1) aged between 18-60 years; 2) smoked, on average, a minimum of 10 cigarettes per day regularly over the past 12-months; 3) met criteria for moderate or above Tobacco Use Disorder as defined by the DSM-5 (APA, 2013); 5) self-reported being motivated to make a quit attempt during the training stage of the intervention; 6) had computer and internet access and; 7) 


\section{INHIBITORY CONTROL TRAINING AND SMOKING}

completed at least Year 9 (or equivalent) schooling; a proxy to rule out any intellectual disabilities which can interfere with cognitive task performance (Bexkens, Ruzzano, Collot d'Escury- Koenigs, Van der Molen, \& Huizenga, 2014). Participants were excluded if they: 1) primarily used electronic cigarettes; 2) reported a non-smoking period of two-weeks or more in the past three-months; 3) were using anti-craving medication; 4) used nicotine replacement therapy (NRT) during the intervention period; 5) reported problematic alcohol or drug use other than tobacco; 6) reported a traumatic or acquired brain injury or loss of consciousness for more than 30 minutes and; 7) reported current use of psychotropic medication such as anti-depressant, anti-psychotic and/or anxiolytic medication as these have been shown to interfere with cognitive task performance (Dias et al., 2012; Stewart, 2005).

\section{Go/No-Go Training Tasks}

Smoking-specific GNG task. The smoking-specific GNG task was originally developed by Lawrence et al. (2015) and was modified to incorporate images of smoking using an online JavaScript library (de Leeuw, 2015). The task consisted of nine salient smoking-related images, nine relaxing images (e.g., depicting relaxing/enjoyable activities such as sitting by a river or lying in a hammock), and 18 neutral images (e.g., clothing). Participants were instructed to indicate as quickly and as accurately as possible if an image was located on the left or right side of the screen by pressing the keys "C" and "M" respectively (Go trials). On 50\% of trials, the frame surrounding the picture was bold, which was a signal for participants to withhold their response (No-Go trials). All smoking images were consistently paired with No-Go trials (100\% No-Go), all relaxing images were consistently paired with Go trials (100\% Go), and 50\% of neutral images were paired with No-Go trials (50\% Go/No-Go). This was to prevent participants from easily identifying the associative rules of the task and to ensure the task remained challenging and engaging. Each of the 36 images were presented once per block and participants completed a total of six blocks per training session. After each block, participants were provided with feedback (accuracy and mean Go reaction time) and were encouraged to try and beat their own score to increase motivation and task adherence. Time between blocks was self-paced and each training session took approximately 10-minutes. 


\section{INHIBITORY CONTROL TRAINING AND SMOKING}

Control GNG task. The control GNG task was identical to the smoking-specific task except there were no smoking and relaxation images. Instead, the smoking and relaxation images were replaced with 18 images of household objects. Go and No-Go trials consisted of an equal mix of neutral and household images (50\% Go/No-Go).

\section{Measures}

Stop-Signal Task (SST; Verbruggen \& Logan, 2008b). All images in the SST were smokingrelated and were different from the images used in the smoking-specific GNG task. A total of 16 images (eight pairs) were embedded into the SST, where one image of the pair was a cigarette pointing to the left, and the second image was its mirror image pointing to the right. Using a laptop, participants were presented with a fixation cross ('+') in the centre of a white screen for 500ms. Following, a Go stimulus (i.e., one of the 16 cigarette images) appeared on the screen for $1000 \mathrm{~ms}$, followed by a blank white screen for $1000 \mathrm{~ms}$. Participants were instructed to determine as quickly and as accurately as possible if the lit end of the cigarette was pointing to the left or the right by pressing the computer key "C" and "M" respectively. Participants were also instructed to withhold their response if the Go stimulus was followed by a pair of red lines across the screen (i.e., the stop signal). The stop signal was presented randomly, and on a minority of trials (25\%), to prevent participants from predicting when it would occur. The stop-signal also occurred at a variable delay (Stop-Signal Delay; SSD) after the target stimulus appeared, and the length of this delay was contingent upon the participant's trial accuracy. After a successful stop trial, the SSD increased by 50ms, whereas after a failed stop trial, the SSD decreased by $50 \mathrm{~ms}$. This staircase method converges upon a SSD which results in an inhibition success rate of approximately 50\%. The Stop Signal Reaction Time (SSRT) was calculated by subtracting the SSD from the mean reaction time to Go stimuli and, a longer SSRT reflects poorer inhibitory control. The SST consisted of one block of 194 trials with each of the 16 images presented 12 times and participants completed one practice block of 10 trials prior to commencing the SST.

The Barratt Impulsiveness Scale-11 (BIS-11; Patton, Stanford, \& Barratt, 1995). The BIS11 , consisting of 30 items scored on a 4-point scale, is a commonly used measure which assesses 


\section{INHIBITORY CONTROL TRAINING AND SMOKING}

different types of trait impulsivity on three main subscales: motor impulsiveness (e.g., "I do things without thinking;"), attentional impulsiveness (e.g., "I concentrate easily;") and non-planning impulsiveness (e.g., "I plan tasks carefully;"). The Total BIS-11 score is the sum of the subscale scores and showed acceptable reliability $(\alpha=.79)$.

\section{The Fagerström Test of Nicotine Dependence (FTND; Heatherton, Kozlowski, Frecker, \&}

Fagerström, 1991). The FTND is a six-item self-report scale which assesses nicotine dependence and scores range from 0 to 10, with higher scores indicating greater dependence. The FTND has been validated in smokers from the general population and in clinical samples and showed acceptable reliability $(\alpha=.72)$.

Timeline Follow-Back (TLFB; Robinson, Sobell, Sobell, \& Leo, 2014). The TLFB is a calendar-based assessment of daily cigarette use for periods of time ranging from 1 to 12 months prior to assessment. Initially developed to assess alcohol consumption, the TLFB has since been utilised to assess a variety of substance use inclusive of cigarette use (Robinson et al., 2014) and found to be reliable. Memory aids are used to enhance recall of certain time-periods in order to retrospectively estimate number of cigarettes used for each date. The TLFB for cigarettes has shown high test-retest reliability and temporal stability across both clinical and non-clinical participants (Robinson et al., 2014).

\section{Procedure}

Interested participants were invited to contact the research team via email and were screened via a structured survey over the phone/online to determine their eligibility. Eligible participants were invited to participate and attended a face-to-face meeting at the University. Participants were instructed to abstain from smoking for one-hour prior to the start of the meeting in order to ameliorate the acute effects of nicotine on cognitive performance without introducing withdrawal effects (Houlihan, Pritchard, \& Robinson, 1996, 2001). At the outset of this meeting, the study and its requirements were explained to participants and informed consent was obtained. Participants completed demographic and baseline questionnaires, a one-month retrospective recall diary of daily 


\section{INHIBITORY CONTROL TRAINING AND SMOKING}

cigarette consumption and the Stop-Signal Task. Participants were then reminded that they would be required to cease smoking, or reduce towards cessation, at any point during the two-week training program. We did not impose an abrupt cessation target upon participants, unless this was their preference, as research has demonstrated that gradual reduction towards eventual abstinence is an effective method for dependent smokers (Asfar, Ebbert, Klesges, \& Relyea, 2011; Ebbert, Hughes, West, \& et al., 2015; Hughes \& Carpenter, 2006; Klemperer \& Hughes, 2015; Wang et al., 2008) and, our two pilot studies indicated that participants wanted flexibility to select their own quit dates (Guo, 2018).

Participants were told that they would be randomly allocated to receive one of two brain training tasks, as the aim of the study was to investigate which was more effective. The types of images included in the training were not specified to prevent participants from identifying if they were in the intervention or control condition. In this respect, the study enabled a reasonable level of blinding as to which task was considered to be the intervention. Participants then began the online task and were automatically randomised to receive either the intervention or control GNG training task via a pre-computed randomisation procedure. Upon finishing the task, participants were instructed to complete the online training task once per day for the next 13 days, totalling 14 sessions, and were requested to abstain from smoking for two-hours prior to each session to reduce the acute effects of nicotine on cognitive performance without introducing withdrawal effects (Houlihan et al., 1996, 2001). Participants were advised that they had 24-hours to complete each of their daily training sessions and could do so at a place and time of their convenience. If participants missed a session, they were not given the opportunity to complete additional sessions. Twice per week, participants were sent text reminders to complete the task. All data from the online task and outcome measures were securely stored on the University server and linked to an anonymous participant ID number such that only de-identified data were available to researchers. The data was checked for task performance accuracy and participant adherence to the training protocol by a research assistant who was independent from investigators and not involved in data collection or analyses. 


\section{INHIBITORY CONTROL TRAINING AND SMOKING}

Upon completion of the training period (T2), participants were contacted via telephone by a researcher naïve to the group randomisation (i.e., a different researcher to the one who conducted the baseline face-to-face interview). During these phone interviews, participants were asked to provide details about their daily use of cigarettes and nicotine replacement therapies or anti-craving medications during the past 14-days of training. We had two follow-up time points which occurred at one-month (T3) and three-months (T4) after T2. Telephone interviews at T3 and T4 were conducted in the same manner as T2. At the completion of each time point, participants were mailed a $\$ 20$ gift card. At the conclusion of the data collection period, participants in the control condition were offered the opportunity to complete the smoking-specific ICT program.

\section{Analytic Strategy}

All analyses were conducted using IBM Statistical Package for Social Sciences (SPSS, Version 25) unless otherwise stated. An a priori power analysis using G*Power (Faul, Erdfelder, Lang, \& Buchner, 2007) indicated that a minimum of 92 participants were required to detect a medium effect size $(d=.50)$, with an alpha set at 0.05 and power set at .80 (see Staiger et al., 2018). Our effect size estimate was drawn from Lawrence et al. (2015) weight-loss reduction outcome as no previous ICT studies have measured abstinence.

To examine if there were any significant differences between conditions on GNG performance and adherence, one-way ANOVAs were conducted. Percent days abstinent was chosen as the most appropriate outcome measure to assess our primary hypothesis as only five participants reported complete cessation (see Staiger et al., 2018 for a discussion of the analysis plan of this variable). Given the strong skew, percent days abstinent was analysed using the non-parametric Mann-Whitney U test. Our primary hypothesis relating to reduction in daily cigarette consumption was analysed using a 2 (condition: intervention, control) x 4 (time: baseline, T2, T3 and T4) mixed-design ANOVA. For our primary analyses, Bayes factors were calculated using JASP (2018), using non-informed default priors. Our moderator hypotheses were separately analysed using the SPSS macro PROCESS (Hayes, 2012), with condition as the predictor variable, average daily cigarette consumption at T2, T3 and T4 


\section{INHIBITORY CONTROL TRAINING AND SMOKING}

as separate dependent variables, baseline cigarette consumption as a covariate and trait impulsivity (BIS-11), inhibitory control (SSRT), training dose, gender and age as separate moderator variables. Any significant moderation effects were examined using the Johnson-Neyman (JN) technique. The JN technique determines the values of the moderator where the $95 \%$ confidence interval for the expected difference in cigarette consumption between conditions at a particular follow-up point (after adjusting for cigarette consumption at baseline) does not include zero. Thirteen participants reported that they used a smoking cessation treatment at some point during T3 or T4. Results did not significantly differ when we controlled for the use of other treatment or excluded these participants and therefore, they were retained for all analyses.

\section{Results}

\section{Participant Flow}

Figure 1 illustrates the flow of participants through each stage of the study. A total of 164 participants met eligibility criteria and were invited to participate. Although 110 participants were recruited into the study and randomised to the intervention or control condition, two participants formally withdrew all their data from the study during the training period and one individual was deemed ineligible to participate in the study as they used NRT during the training period. As such, the final intent-to treat sample was 107.

\section{[Insert Figure 1]}

\section{Missing Data}

Missing values analysis indicated that a total of four participants (3.8\%) had missing TLFB data at T2, six participants (5.6\%) at T3 and 13 participants (12.1\%) at T4 and all TLFB missing data was due to attrition. One-way ANOVAs were conducted to compare missing and non-missing groups on all baseline characteristics and no significant differences were identified. Missing value analysis indicated that data were consistent with a missing completely at random (MCAR) pattern $\left(\chi^{2}=36.08\right.$, $p=.33$ ) and therefore, a single imputation approach using the expectation maximisation algorithm 


\section{INHIBITORY CONTROL TRAINING AND SMOKING}

was used which is considered robust when data is MCAR (Enders, 2010; Schafer \& Graham, 2002). Analyses were conducted on the imputed and non-imputed datasets and comparisons yielded no significant differences in the interpretation of the results (i.e., magnitude, directions, statistical significance of effects were consistent). As such, all analyses reported are conducted using the imputed dataset to maximise the sample size available for analysis.

\section{GNG Training Performance}

Task adherence and accuracy were high, indicating that participants in both conditions were engaged by the training and performed well (see Table 2). As per Lawrence et al. (2015), repeated measures ANOVA were used to examine training performance and learning of stimulus specific Go or No-Go associations for participants in the intervention condition over time (see Supplementary Table

2). Results indicated that participants showed learning of stimulus specific No-Go associations, demonstrated by significantly greater accuracy to the $100 \%$ No-Go stimuli (i.e., smoking-related images) compared to the $50 \%$ No-Go stimuli (i.e., clothes). However, reaction time did not significantly differ for $100 \%$ Go stimuli (i.e., relaxing images) compared with 50\% Go stimuli (i.e., neutral images such as clothes).

\section{[Insert Table 2]}

\section{Primary Hypothesis: Percent Days Abstinent}

Table 3 shows the percent days abstinent for participants in both conditions. Few participants reported 100 percent days abstinence at $\mathrm{T} 3$ (intervention $=6 \%$; control $=2 \%$ ), or $\mathrm{T} 4$ (intervention $=$ $7 \%$; control $=2 \%$ ). The Mann-Whitney $\mathrm{U}$ test indicated that the mean rank for percent days abstinent in the intervention condition did not significantly differ from the control condition at T2 $(U=$ $\left.1611.00, z=1.86, p=.06, r=.18, \mathrm{BF}^{10}=1.3\right), \mathrm{T} 3\left(U=1573.50, z=1.40, p=.16, r=.14, \mathrm{BF}^{10}=\right.$ $.59)$ and $\mathrm{T} 4\left(U=1583.00, z=1.45, p=.14, r=.14, \mathrm{BF}^{10}=.66\right)$.

\section{[Insert Table 3]}




\section{INHIBITORY CONTROL TRAINING AND SMOKING}

\section{Primary Hypothesis: Cigarette Reduction}

A mixed-design ANOVA revealed that the hypothesised time $\mathrm{x}$ condition interaction was not significant $\left(F(3,103)=.33, p=.80, \eta_{p}{ }^{2}=.01, \mathrm{BF}^{10}=0.04\right)$ and there was no main effect of condition $\left(F(3,105)=.82, p=.37, \eta_{p}{ }^{2}=.01, \mathrm{BF}^{10}=0.31\right)$. However, there was a significant main effect of time $\left(F(3,103)=52.66, p<.01, \eta_{p}{ }^{2}=.61, \mathrm{BF}^{10}>99\right)$, indicating that for both conditions, cigarette consumption significantly decreased from baseline to $\mathrm{T} 2\left(t(106)=12.50, p<.01, d=.83, \mathrm{BF}^{10}>99\right.$, mean difference $=5.43,95 \% \mathrm{CI}[4.57-6.30])$, baseline to $\mathrm{T} 3\left(t(106)=9.64, p<.01, d=.72, \mathrm{BF}^{10}>\right.$ 99 , mean difference $=5.55,95 \% \mathrm{CI}[4.41-6.70])$ and baseline to $\mathrm{T} 4(t(106)=7.64, p<.01, d=.62$, $\mathrm{BF}^{10}>99$, mean difference $\left.=5.04,95 \% \mathrm{CI}[3.63-6.18]\right)$. Cigarette consumption did not significantly differ between conditions at $\mathrm{T} 2, \mathrm{~T} 3$ or $\mathrm{T} 4\left(p>.05, \mathrm{BF}^{10}<.33\right)$ and the magnitude of group differences in cigarette consumption are displayed in Figure 2.

\section{[Insert Figure 2]}

\section{Secondary Hypotheses: Moderation of Condition by Impulsivity}

Separate moderated regression analyses indicated that the relationship between condition and cigarette consumption measured at T2, T3 and T4 was not significantly moderated by SSRT, attentional impulsivity, motor impulsivity and non-planning impulsivity (see Table 4).

\section{[Insert Table 4]}

\section{Exploratory Analyses: Moderation of Condition by Dose, Gender and Age}

Separate moderated regression analyses indicated that the relationship between condition and cigarette consumption measured at $\mathrm{T} 2, \mathrm{~T} 3$ and $\mathrm{T} 4$ was not significantly moderated by training dose or gender (see Supplementary Table 3). However, the magnitude of the difference between the two tasks in daily cigarette consumption at $\mathrm{T} 2, \mathrm{~T} 3$ and $\mathrm{T} 4$ was significantly moderated by age, suggesting that smoking-specific ICT may be effective at reducing daily cigarette consumption for younger participants only (see Supplementary Table 4). Yet, it should be noted that these results (T2: $p=.024$, 


\section{INHIBITORY CONTROL TRAINING AND SMOKING}

T3: $p=.018, \mathrm{~T} 4: p=.008$ ) were no longer statistically significant after adjustment for multiple comparisons using the Bonferroni method (9 comparisons, $\alpha=.006$ ).

\section{Discussion}

This pre-registered clinical trial was the first to examine the real-world effectiveness of ICT on cigarette smoking. It also investigated whether individual differences in impulsivity would moderate the effectiveness of ICT. We found no significant differences between the intervention and control condition on percent days abstinent or daily cigarette consumption although, there was an overall significant decrease in daily cigarette consumption across both conditions. Second, we found no significant moderating effects of impulsivity on the relationship between cigarette consumption and smoking-specific ICT.

Across both conditions, the majority of participants reported zero days abstinence, whereas only a minority of participants reported complete abstinence and, analyses indicated that there were no significant group differences in percent days abstinent at any post-intervention time-points. As such, our primary hypothesis that smoking-specific ICT would result in greater percent days abstinent compared to the control task was not supported. However, given the well-established difficulties of achieving abstinence (Hughes et al., 2008; Piasecki, 2006), for ICT to improve cessation rates it may need to be supported by pharmacotherapy to address the cravings and withdrawal symptoms typically associated with early nicotine cessation. Indeed, several recent Cochrane reviews have demonstrated that combining pharmacological and behavioural interventions increase the likelihood of abstinence compared to when each is administered alone (Stead, Koilpillai, \& Lancaster, 2015; Stead \& Lancaster, 2012; Stead \& Lancaster, 2015). Nonetheless, as this is the first study to investigate the effect of ICT on abstinence, it provides initial evidence that smoking-specific ICT, at least as delivered here, may be ineffective as a standalone treatment option to achieve smoking cessation.

With regards to our primary hypothesis concerning smoking reduction, we found that both conditions reported significant reductions in daily cigarette consumption at all post-intervention time points; however, there were no significant differences between conditions. This main effect may be 


\section{INHIBITORY CONTROL TRAINING AND SMOKING}

attributable to a variety of features common to both tasks including the requirement to make a quit or reduction attempt (Balmford, Borland, \& Burney, 2010; de Vries, Eggers, \& Bolman, 2013), or nonspecific factors, such as the self-monitoring of daily cigarette consumption or having the motivation to quit/reduce smoking (Curry, Wagner, \& Grothaus, 1990; Mcfall \& Hammen, 1971). However, a limitation in the design of our study was that we did not include an additional, no-intervention (passive) control group. As such, we are unable to determine whether the reductions in cigarette consumption are attributable to these aforementioned common features or, whether they relate to features inherent in the two GNG tasks. While it is not expected that a non-smoking specific GNG task would impact smoking behaviour (e.g., Guerrieri et al., 2012; Lawrence et al., 2015; Oomen et al., 2018), additional studies that incorporate passive control groups may assist in disentangling these findings.

Our secondary hypothesis that impulsivity would moderate the relationship between smokingspecific ICT and daily cigarette consumption was not supported. Given that only one study (Houben, 2011) has examined the moderating role of inhibitory control on ICT effectiveness, our null findings may indicate that the effectiveness of ICT is not influenced by an individual's level of pre-existing capacity for inhibitory control or alternatively, could be attributable to differences in methodology between the two studies. For example, Houben (2011) measured unhealthy food consumption immediately following ICT, whereas we assessed cigarette consumption over much longer time periods (i.e, up to three-months). As such, pre-existing levels of inhibitory control may only have an influence on the behavioural outcomes of ICT in the immediate-term, but not in the long-term. Second, Houben (2011) measured baseline inhibitory control using a general SST, whereas we used a smoking-specific SST. While a smoking-specific SST is expected to be a more sensitive measure of inhibitory control relevant to smoking (Houben, Nederkoorn, \& Jansen, 2014; Nederkoorn, Coelho, Guerrieri, Houben, \& Jansen, 2012; Svaldi, Naumann, Trentowska, \& Schmitz, 2014), it is possible that the influence of baseline inhibitory control on outcome is only detected in general SSTs. 


\section{INHIBITORY CONTROL TRAINING AND SMOKING}

Similarly, baseline trait impulsivity had no influence on the effectiveness of ICT. However, our findings are consistent with another study that purports to address impulse control via mindfulness training in those who are substance dependent (Staiger, Dawe, Richardson, Hall, \& Kambouropoulos, 2014). In this study, individuals who reported improvements in mindfulness also reported less drug use at follow-up irrespective of their levels of trait impulsivity at baseline. As such, an individual's level of impulsivity may not influence their capacity to improve inhibitory control via ICT or alternatively, it is possible that ICT exerts its influence on behaviour via devaluation of the smoking stimuli (which will be the focus of an additional paper) rather than changes in impulse control. Nonetheless, given that this is the first study to investigate the role of trait impulsivity on ICT effectiveness further investigation may be warranted. Finally, although gender and dose did not influence the effectiveness of the intervention, there was some weak evidence from the exploratory moderator analyses suggesting that smoking-specific ICT may be effective at reducing daily cigarette consumption for younger participants only (see Supplementary Results and Discussion). However, we recommend caution before drawing any conclusions regarding the importance of age as the effect was no longer statistically significant after adjustment for multiple comparisons error using the Bonferroni method.

A number of caveats regarding the methodology are warranted. First, while 12-month outcomes are preferable (West et al., 2005), we wanted to firstly establish whether smoking-specific ICT had any short-term effects before moving to a costly, long-term trial. Additional research is needed to investigate the influence of ICT on smoking beyond three-months post-intervention. Second, although self-reports of cigarette consumption are considered reliable, a lack of biochemical verification may have limited the accuracy of our data (Gorber, Schofield-Hurwitz, Hardt, Levasseur, \& Tremblay, 2009; Hatziandreu et al., 1989; Patrick et al., 1994). However, as participants were blinded to condition and were also unaware that a control condition existed, any misreporting of data would likely be balanced across both conditions. Third, as we did not impose a specific quit date, nor require abrupt cessation, there was substantial variability as to when participants reduced or ceased 


\section{INHIBITORY CONTROL TRAINING AND SMOKING}

smoking and further research is required to examine the importance of abstinence and reduction goals in relation to the effectiveness ICT. Fourth, unlike ICT in Lawrence et al. (2015) where 100\% of Go images were towards healthy food, there is no obvious 'healthy' opposite of smoking and therefore, our choice of relaxing stimuli as Go images may not have been effective in training a 'healthy alternative' to smoking. Furthermore, the training task performance data suggest that smoking-specific participants did not learn to 'Go' to these relaxing images because they were no faster to respond to them compared to the non-predictive filler images. Given this, future research might consider increasing the proportion of smoking-related No-Go stimuli in lieu of Go stimuli (Chen, Veling, Dijksterhuis, \& Holland, 2016; Veling et al., 2014). This is of course an empirical question and warrants further investigation. Finally, our control task did not include smoking-related images as we wanted to avoid the potential confounds associated with executing responses to smoking images in a control condition (see Adams et al. 2017 for a discussion of this issue in relation to food); however, our intervention task did include smoking-related images, and this may have increased craving. Therefore, in addition to passive control groups, future research may want to also investigate the use of a control condition matched for cue-exposure (such as passive viewing of the same images presented in the intervention task).

Future research might also consider allowing participants to select their own smoking-related images, as research has found that when stimuli are more impulse evoking, ICT can be more effective (Chen et al., 2016; Veling et al., 2011; Veling et al., 2013). Although we conducted a pilot study with heavy smokers to ensure that the smoking-related images included in this trial were highly salient and elicited cigarette craving (Guo, 2018), it is possible that if smoking stimuli are personalised for each participant, ICT may be more effective. Indeed, studies have shown that the more similar the stimuli is to the preferred alcoholic beverage the stronger the reactivity and craving to the cue (Staiger \& White, 1991). This issue awaits further investigation; however, given the fast pace of technological advancements, future ICT studies delivered via mobile devices may enable participants to personalise their own Go and No-Go images and enhance the ecological validity of the intervention. 


\section{INHIBITORY CONTROL TRAINING AND SMOKING}

To conclude, this study found that smoking-specific ICT did not help smokers achieve abstinence or reduce their cigarette consumption over and above the active control task; however, both conditions reported significant reductions in daily cigarette consumption which were sustained at three-months follow-up. Second, we did not find evidence to suggest that impulsivity moderates the effectiveness of ICT. While exploratory moderator analyses provided some weak evidence that younger participants may benefit more from smoking-specific ICT, these findings were no longer statistically significant after adjusting for multiple comparisons using the Bonferroni method and we look to future research to examine the role of age in ICT. As this was the first real-world investigation into ICT for smoking, we have provided several suggestions that future research may wish to incorporate, and we eagerly await to see if these suggestions augment the effectiveness of ICT for smoking cessation and reduction.

Disclosures: All authors have no conflict of interest to declare.

Funding: This research did not receive grants from any funding agency in the public, commercial or not-for-profit sectors. Funding solely provided by Deakin University. 


\section{INHIBITORY CONTROL TRAINING AND SMOKING}

\section{References}

Adams, R. C., Lawrence, N. S., Verbruggen, F., \& Chambers, C. D. (2017). Training response inhibition to reduce food consumption: Mechanisms, stimulus specificity and appropriate training protocols. Appetite, 109, 11-23. doi:https://doi.org/10.1016/j.appet.2016.11.014

Adams, S., Mokrysz, C., Attwood, A. S., \& Munafò, M. R. (2017). Resisting the urge to smoke: inhibitory control training in cigarette smokers. Royal Society Open Science, 4(8), 170045.

Allom, V., \& Mullan, B. (2015). Two inhibitory control training interventions designed to improve eating behaviour and determine mechanisms of change. Appetite, 89, 282-290. doi:10.1016/j.appet.2015.02.022

Allom, V., Mullan, B., \& Hagger, M. (2015). Does inhibitory control training improve health behaviour? A meta-analysis. Health Psychology Review, 10(2), 168-186. doi:10.1080/17437199.2015.1051078

Altman, D. G., \& Schulz, K. F. (2001). Concealing treatment allocation in randomised trials. BMJ, $323,446-447$.

Appelbaum, M., Kline, R. B., Rao, S. M., Cooper, H., Mayo-Wilson, E., \& Nezu, A. M. (2018). Journal article reporting standards for quantitative research in psychology: The APA Publications and Communications Board task force report. American Psychologist, 73(1), 325.

American Psychiatric Association. (2013). Diagnostic and statistical manual of mental disorders $\left(5^{\text {th }}\right.$ ed.). Arlington, VA: American Psychiatric Publishing.

Asfar, T., Ebbert, J. O., Klesges, R. C., \& Relyea, G. E. (2011). Do smoking reduction interventions promote cessation in smokers not ready to quit? Addictive Behaviors, 36(7), 764-768. doi:10.1016/j.addbeh.2011.02.003

Balmford, J., Borland, R., \& Burney, S. (2010). The influence of having a quit date on prediction of smoking cessation outcome. Health Education Research, 25(4), 698-706. 


\section{INHIBITORY CONTROL TRAINING AND SMOKING}

Bexkens, A., Ruzzano, L., Collot d'Escury- Koenigs, A., Van der Molen, M., \& Huizenga, H. (2014). Inhibition deficits in individuals with intellectual disability: A meta- regression analysis. Journal of Intellectual Disability Research, 58(1), 3-16.

Billieux, J., Gay, P., Rochat, L., Khazaal, Y., Zullino, D., \& Van der Linden, M. (2010). Lack of inhibitory control predicts cigarette smoking dependence: Evidence from a non-deprived sample of light to moderate smokers. Drug and Alcohol Dependence, 112(1-2), 164-167.

Bloom, E. L., Matsko, S. V., \& Cimino, C. R. (2013). The relationship between cigarette smoking and impulsivity: A review of personality, behavioral, and neurobiological assessment. Addiction Research \& Theory, 22(5), 386-397. doi:10.3109/16066359.2013.867432

Bos, J., Hayden, M. J., Lum, J. A. G., \& Staiger, P. K. (2019). UPPS-P impulsive personality traits and adolescent cigarette smoking: A meta-analysis. Drug and Alcohol Dependence, 97, 335-

\section{3. https://doi.org/10.1016/j.drugalcdep.2019.01.018}

Bowley, C., Faricy, C., Hegarty, B., Johnstone, S. J., Smith, J. L., Kelly, P. J., \& Rushby, J. A. (2013). The effects of inhibitory control training on alcohol consumption, implicit alcohol-related cognitions and brain electrical activity. International Journal of Psychophysiology, 89(3), 342348. doi:10.1016/j.ijpsycho.2013.04.011

Brehmer, Y., Westerberg, H., \& Bäckman, L. (2012). Working-memory training in younger and older adults: training gains, transfer, and maintenance. Frontiers in human neuroscience, 6, 63.

Cahill, K., Stevens, S., Perera, R., \& Lancaster, T. (2013). Pharmacological interventions for smoking cessation: An overview and network meta- analysis. Cochrane Database of Systematic Reviews, 2013(5), 1-50. doi: 10.1002/14651858.CD009329.pub2.

Calero, M. D., \& Navarro, E. (2007). Cognitive plasticity as a modulating variable on the effects of memory training in elderly persons. Archives Of Clinical Neuropsychology: The Official Journal Of The National Academy Of Neuropsychologists, 22(1), 63-72. 


\section{INHIBITORY CONTROL TRAINING AND SMOKING}

Chen, Z., Veling, H., Dijksterhuis, A., \& Holland, R. W. (2016). How does not responding to appetitive stimuli cause devaluation: Evaluative conditioning or response inhibition? Journal of Experimental Psychology: General, 145(12), 1687-1701.

Clark, R., Hazeltine, E., Freedberg, M., \& Voss, M. W. (2018). Age differences in episodic associative learning. Psychology and Aging, 33(1), 144.

Cohen, J. (1992). A power primer. Psychological Bulletin, 112(1), 155.

Curry, S., Wagner, E. H., \& Grothaus, L. C. (1990). Intrinsic and extrinsic motivation for smoking cessation. Journal of Consulting and Clinical Psychology, 58(3), 310-316.

Dahlin, E., Nyberg, L., Bäckman, L., \& Neely, A. S. (2008). Plasticity of executive functioning in young and older adults: immediate training gains, transfer, and long-term maintenance. Psychology and Aging, 23(4), 720.

de Leeuw, J. R. (2015). jsPsych: A JavaScript library for creating behavioral experiments in a web browser. Behavior Research Methods, 47(1), 1-12. doi:10.3758/s13428-014-0458-y.

de Vries, H., Eggers, S. M., \& Bolman, C. (2013). The role of action planning and plan enactment for smoking cessation. BMC Public Health, 13(393), 1-11.

Dias, V. V., Balanzá- Martinez, V., Soeiro- de- Souza, M., Moreno, R., Figueira, M., MachadoVieira, R., \& Vieta, E. (2012). Pharmacological approaches in bipolar disorders and the impact on cognition: A critical overview. Acta Psychiatrica Scandinavica, 126(5), 315-331.

Ebbert, J. O., Hughes, J. R., \& West, R. J. (2015). Effect of varenicline on smoking cessation through smoking reduction: A randomized clinical trial. JAMA, 313(7), 687-694. doi:10.1001/jama.2015.280

Eliasson, B., Hjalmarson, A., Kruse, E., Landfeldt, B., \& Westin, Å. (2001). Effect of smoking reduction and cessation on cardiovascular risk factors. nicotine \& tobacco research, 3(3), 249255.

Enders, C. K. (2010). Applied missing data analysis: New York, NY, US: Guilford press. 


\section{INHIBITORY CONTROL TRAINING AND SMOKING}

Everitt, B. J., \& Robbins, T. W. (2005). Neural systems of reinforcement for drug addiction: from actions to habits to compulsion. Nature neuroscience, 8(11), 1481.

Faul, F., Erdfelder, E., Lang, A.-G., \& Buchner, A. (2007). G* Power 3: A flexible statistical power analysis program for the social, behavioral, and biomedical sciences. Behavior Research Methods, 39(2), 175-191.

Gerber, Y., Myers, V., \& Goldbourt, U. (2012). Smoking reduction at midlife and lifetime mortality risk in men: a prospective cohort study. American journal of epidemiology, 175(10), 10061012.

Glass, J. M., Buu, A., Adams, K. M., Nigg, J. T., Puttler, L. I., Jester, J. M., \& Zucker, R. A. (2009). Effects of alcoholism severity and smoking on executive neurocognitive function. Addiction, 104(1), 38-48.

Goldstein, R. Z., \& Volkow, N. D. (2002). Drug addiction and its underlying neurobiological basis: Neuroimaging evidence for the involvement of the frontal cortex. American Journal of Psychiatry, 159(10), 1642-1652.

Gorber, S. C., Schofield-Hurwitz, S., Hardt, J., Levasseur, G., \& Tremblay, M. (2009). The accuracy of self-reported smoking: a systematic review of the relationship between self-reported and cotinine-assessed smoking status. Nicotine \& Tobacco Research, 11(1), 12-24.

Guerrieri, R., Nederkoorn, C., \& Jansen, A. (2012). Disinhibition is easier learned than inhibition. The effects of (dis) inhibition training on food intake. Appetite, 59(1), 96-99.

Guerrieri, R., Nederkoorn, C., Schrooten, M., Martijn, C., \& Jansen, A. (2009). Inducing impulsivity leads high and low restrained eaters into overeating, whereas current dieters stick to their diet. Appetite, 53(1), 93-100.

Guo, K. (2018). Impulsivity and smoking: Development of a smoking cessation treatment. (Doctoral Dissertation, Deakin University, Geelong, Australia). Retrieved from http://dro.deakin.edu.au/eserv/DU:30116554/guo-impulsivityandsmoking-2018.pdf 


\section{INHIBITORY CONTROL TRAINING AND SMOKING}

Hall, P. A. (2012). Executive control resources and frequency of fatty food consumption: Findings from an age-stratified community sample. Health Psychology, 31(2), 235-241. doi: $10.1037 / \mathrm{a} 0025407$

Hatziandreu, E. J., Pierce, J. P., Fiore, M. C., Grise, V., Novotny, T. E., \& Davis, R. M. (1989). The reliability of self-reported cigarette consumption in the United States. American Journal of Public Health, 79(8), 1020-1023.

Hayes, A. F. (2012). PROCESS: A versatile computational tool for observed variable mediation, moderation, and conditional process modeling. Retrieved from http://www.afhayes.com/public/process2012.pdf

Heatherton, T. F., Kozlowski, L. T., Frecker, R. C., \& FAGERSTROM, K. O. (1991). The Fagerström test for nicotine dependence: A revision of the Fagerstrom Tolerance Questionnaire. British Journal of Addiction, 86(9), 1119-1127.

Houben, K. (2011). Overcoming the urge to splurge: Influencing eating behavior by manipulating inhibitory control. Journal of Behavior Therapy and Experimental Psychiatry, 42(3), 384-388. doi:10.1016/j.jbtep.2011.02.008

Houben, K., Havermans, R. C., Nederkoorn, C., \& Jansen, A. (2012). Beer a no-go: Learning to stop responding to alcohol cues reduces alcohol intake via reduced affective associations rather than increased response inhibition. Addiction, 107(7), 1280-1287. doi:10.1111/j.13600443.2012.03827.x

Houben, K., \& Jansen, A. (2011). Training inhibitory control. A recipe for resisting sweet temptations. Appetite, 56(2), 345-349. doi:10.1016/j.appet.2010.12.017

Houben, K., \& Jansen, A. (2015). Chocolate equals stop. Chocolate-specific inhibition training reduces chocolate intake and go associations with chocolate. Appetite, 87, 318-323. doi:10.1016/j.appet.2015.01.005 


\section{INHIBITORY CONTROL TRAINING AND SMOKING}

Houben, K., Nederkoorn, C., \& Jansen, A. (2014). Eating on impulse: The relation between overweight and food-specific inhibitory control. Obesity, 22(5), E6-E8. doi:10.1002/oby.20670

Houben, K., Nederkoorn, C., Wiers, R. W., \& Jansen, A. (2011). Resisting temptation: Decreasing alcohol-related affect and drinking behavior by training response inhibition. Drug and Alcohol Dependence, 116(1-3), 132-136. doi:10.1016/j.drugalcdep.2010.12.011

Houlihan, M. E., Pritchard, W. S., \& Robinson, J. H. (1996). Faster P300 latency after smoking in visual but not auditory oddball tasks. Psychopharmacology, 123(3), 231-238.

Houlihan, M. E., Pritchard, W. S., \& Robinson, J. H. (2001). Effects of smoking/nicotine on performance and event-related potentials during a short-term memory scanning task. Psychopharmacology, 156(4), 388-396.

Hughes, J. R., \& Carpenter, M. J. (2006). Does smoking reduction increase future cessation and decrease disease risk? A qualitative review. Nicotine \& Tobacco Research, 8(6), 739-749.

Hughes, J. R., Peters, E. N., \& Naud, S. (2008). Relapse to smoking after 1 year of abstinence: a metaanalysis. Addictive Behaviors, 33(12), 1516-1520. doi:10.1016/j.addbeh.2008.05.012

JASP Team (2018). JASP (Version 0.9) [Computer software].

Jones, A., Di Lemma, L. C., Robinson, E., Christiansen, P., Nolan, S., Tudur-Smith, C., \& Field, M. (2016). Inhibitory control training for appetitive behaviour change: A meta-analytic investigation of mechanisms of action and moderators of effectiveness. Appetite, 97, 16-28. doi:10.1016/j.appet.2015.11.013

Jones, A., \& Field, M. (2013). The effects of cue-specific inhibition training on alcohol consumption in heavy social drinkers. Experimental and Clinical Psychopharmacology, 21(1), 8-16. doi:10.1037/a0030683

Jones, A., McGrath, E., Robinson, E., Houben, K., Nederkoorn, C., \& Field, M. (2018). A randomised controlled trial of inhibitory control training for the reduction of alcohol consumption in 


\section{INHIBITORY CONTROL TRAINING AND SMOKING}

problem drinkers. Journal of Consulting and Clinical Psychology, 86(12), 991-1004. http://dx.doi.org/10.1037/ccp0000312

Jones, S., Nyberg, L., Sandblom, J., Neely, A. S., Ingvar, M., Petersson, K. M., \& Bäckman, L. (2006). Cognitive and neural plasticity in aging: general and task-specific limitations. Neuroscience \& Biobehavioral Reviews, 30(6), 864-871.

Kale, D., Stautz, K., \& Cooper, A. (2018). Impulsivity related personality traits and cigarette smoking in adults: A meta-analysis using the UPPS-P model of impulsivity and reward sensitivity. Drug and Alcohol Dependence, 185, 149-167. https://doi.org/10.1016/j.drugalcdep.2018.01.003

Klemperer, E. M., \& Hughes, J. R. (2015). Does the magnitude of reduction in cigarettes per day predict smoking cessation? A qualitative review. nicotine \& tobacco research, 18(1), 88-92.

Kray, J., \& Eppinger, B. (2006). Effects of associative learning on age differences in task-set switching. Acta Psychologica, 123(3), 187-203.

Krishnan-Sarin, S., Reynolds, B., Duhig, A. M., Smith, A., Liss, T., McFetridge, A., . . Potenza, M. N. (2007). Behavioral impulsivity predicts treatment outcome in a smoking cessation program for adolescent smokers. Drug and Alcohol Dependence, 88(1), 79-82.

Lancaster, T., \& Stead, L. F. (2017). Individual behavioural counselling for smoking cessation. Cochrane Database of Systematic Reviews, 2017(3), 1-72.

Lawrence, N. S., O'Sullivan, J., Parslow, D., Javaid, M., Adams, R. C., Chambers, C. D., .. . Verbruggen, F. (2015). Training response inhibition to food is associated with weight loss and reduced energy intake. Appetite, 95, 17-28. doi:10.1016/j.appet.2015.06.009

Lawrence, N. S., Verbruggen, F., Morrison, S., Adams, R. C., \& Chambers, C. D. (2015). Stopping to food can reduce intake. Effects of stimulus-specificity and individual differences in dietary restraint. Appetite, 85, 91-103. 


\section{INHIBITORY CONTROL TRAINING AND SMOKING}

Lee, P. N. (2013). The effect of reducing the number of cigarettes smoked on risk of lung cancer, COPD, cardiovascular disease and FEV1-A review. Regulatory Toxicology and Pharmacology, 67(3), 372-381.

Lillard, A. S., \& Erisir, A. (2011). Old dogs learning new tricks: Neuroplasticity beyond the juvenile period. Developmental Review, 31(4), 207-239. doi:https://doi.org/10.1016/j.dr.2011.07.008

Linke, S., Brown, A., \& Wallace, P. (2004). Down your drink: A web-based intervention for people with excessive alcohol consumption. Alcohol and Alcoholism, 39(1), 29-32. doi:10.1093/alcalc/agh004

Logan, G. D. (1988). Toward an instance theory of automatization. Psychological Review, 95(4), 492527.

Logan, G. D., \& Cowan, W. B. (1984). On the ability to inhibit thought and action: A theory of an act of control. Psychological Review, 91, 295-327. doi:10.1037/0033-295X.91.3.295

Logan, G. D., Cowan, W. B., \& Davis, K. A. (1984). On the ability to inhibit simple and choice reaction time responses: A model and a method. Journal of Experimental Psychology: Human Perception and Performance, 10(2), 276.

Lotan, K., Goldbourt, U., \& Gerber, Y. (2017). Smoking Status and Incidence of Cancer After Myocardial Infarction: A Follow-Up Study of over 20 Years. The American journal of medicine, 130(9), 1084-1091.

Luijten, M., Machielsen, M. W., Veltman, D. J., Hester, R., Haan, L. d., \& Franken, I. H. (2014). Systematic review of ERP and fMRI studies investigating inhibitory control and error processing in people with substance dependence and behavioural addictions. Journal of Psychiatry and Neuroscience, 39(3), 149-169.

Lustig, C., Shah, P., Seidler, R., \& Reuter-Lorenz, P. A. (2009). Aging, training, and the brain: A review and future directions. Neuropsychology review, 19(4), 504-522. doi:10.1007/s11065009-9119-9 


\section{INHIBITORY CONTROL TRAINING AND SMOKING}

Mcfall, R. M., \& Hammen, C. L. (1971). Motivation, structure, and self-monitoring: Role of nonspecific factors in smoking reduction. Journal of Consulting and Clinical Psychology, $37(1), 80$.

Nederkoorn, C., Coelho, J. S., Guerrieri, R., Houben, K., \& Jansen, A. (2012). Specificity of the failure to inhibit responses in overweight children. Appetite(2), 409.

Noack, H., Lövdén, M., Schmiedek, F., \& Lindenberger, U. (2009). Cognitive plasticity in adulthood and old age: gauging the generality of cognitive intervention effects. Restorative Neurology And Neuroscience, 27(5), 435-453. doi:10.3233/RNN-2009-0496

Oomen, D., Grol, M., Spronk, D., Booth, C., \& Fox, E. (2018). Beating uncontrolled eating: Training inhibitory control to reduce food intake and food cue sensitivity. Appetite, 131, 73-83.

Park, D. C., \& Bischof, G. N. (2013). The aging mind: neuroplasticity in response to cognitive training. Dialogues in clinical neuroscience, 15(1), 109.

Patrick, D. L., Cheadle, A., Thompson, D. C., Diehr, P., Koepsell, T., \& Kinne, S. (1994). The validity of self-reported smoking: A review and meta-analysis. American Journal of Public Health, 84(7), 1086-1093.

Patton, J. H., Stanford, M. S., \& Barratt, E. S. (1995). Factor structure of the Barratt Impulsiveness Scale. Journal of Clinical Psychology, 51(6), 768-774.

Perry, J. L., \& Carroll, M. E. (2008). The role of impulsive behavior in drug abuse. Psychopharmacology, 200(1), 1-26.

Piasecki, T. M. (2006). Relapse to smoking. Clinical Psychology Review, 26(2), 196-215. doi:10.1016/j.cpr.2005.11.007

Powell, J., Dawkins, L., West, R., Powell, J., \& Pickering, A. (2010). Relapse to smoking during unaided cessation: Clinical, cognitive and motivational predictors. Psychopharmacology (Berl), 212(4), 537-549. doi:10.1007/s00213-010-1975-8 


\section{INHIBITORY CONTROL TRAINING AND SMOKING}

Robinson, S. M., Sobell, L. C., Sobell, M. B., \& Leo, G. I. (2014). Reliability of the Timeline Followback for cocaine, cannabis, and cigarette use. Psychology of Addictive Behaviors, 28, 154-162. doi:10.1037/a0030992

Schafer, J. L., \& Graham, J. W. (2002). Missing data: our view of the state of the art. Psychological methods, 7(2), 147-177.

Smith, J. L., Mattick, R. P., Jamadar, S. D., \& Iredale, J. M. (2014). Deficits in behavioural inhibition in substance abuse and addiction: A meta-analysis. Drug and Alcohol Dependence, 145, 1-33. doi:10.1016/j.drugalcdep.2014.08.009

Sobell, L. C., \& Sobell, M. B. (1992). Timeline Follow-Back: A technique for assessing self-reported alcohol consumption. In R. Z. Litten \& J. P. Allen (Eds.), Measuring Alcohol Consumption: Psychosocial and Biochemical Methods (pp. 41-72). Totowa: Humana Press.

Spinella, M. (2002). Correlations between orbitofrontal dysfunction and tobacco smoking. Addiction Biology, 7(4), 381-384.

Staiger, P. K., Dawe, S., Richardson, B., Hall, K., \& Kambouropoulos, N. (2014). Modifying the risk associated with an impulsive temperament: a prospective study of drug dependence treatment. Addictive behaviors, 39(11), 1676-1681.

Staiger, P. K., Hayden, M. J., Guo, K., Hughes, L. K., Bos, J., \& Lawrence, N. S. (2018). A randomised controlled trial examining the efficacy of smoking-related response inhibition training in smokers: a study protocol. BMC Public Health, 18(1), 1226. doi:10.1186/s12889018-6109-y

Staiger, P. K., \& White, J. M. (1991). Cue reactivity in alcohol abusers: Stimulus specificity and extinction of the responses. Addictive behaviors, 16(5), 211-221.

Stead, L. F., Koilpillai, P., \& Lancaster, T. (2015). Additional behavioural support as an adjunct to pharmacotherapy for smoking cessation. Cochrane Database of Systematic Reviews, 2015(10), $1-104$. 


\section{INHIBITORY CONTROL TRAINING AND SMOKING}

Stead, L. F., \& Lancaster, T. (2015). Behavioural interventions as adjuncts to pharmacotherapy for smoking cessation. Cochrane Database of Systematic Reviews, 2015(12),1-104.

Stead, L. F., \& Lancaster, T. (2012a). Combined pharmacotherapy and behavioural interventions for smoking cessation. Cochrane Database of Systematic Reviews, 2012(10), 1-91.

Stewart, S. A. (2005). The effects of benzodiazepines on cognition. The Journal of Clinical Psychiatry, 66(Suppl 2), 9-13.

Svaldi, J., Naumann, E., Trentowska, M., \& Schmitz, F. (2014). General and food-specific inhibitory deficits in binge eating disorder. The International Journal Of Eating Disorders, 47(5), 534542. doi:10.1002/eat.22260

Veling, H., Aarts, H., \& Papies, E. K. (2011). Using stop signals to inhibit chronic dieters' responses toward palatable foods. Behavior Research and Therapy, 49(11), 771-780. doi:10.1016/j.brat.2011.08.005

Veling, H., Aarts, H., \& Stroebe, W. (2013). Using stop signals to reduce impulsive choices for palatable unhealthy foods. British Journal of Health Psychology, 18(2), 354-368. doi:10.1111/j.2044-8287.2012.02092.x

Veling, H., Holland, R. W., \& van Knippenberg, A. (2008). When approach motivation and behavioral inhibition collide: Behavior regulation through stimulus devaluation. Journal of Experimental Social Psychology, 44(4), 1013-1019. doi:10.1016/j.jesp.2008.03.004

Veling, H., van Koningsbruggen, G. M., Aarts, H., \& Stroebe, W. (2014). Targeting impulsive processes of eating behavior via the internet. Effects on body weight. Appetite, 78, 102-109. doi:10.1016/j.appet.2014.03.014

Verbruggen, F., Best, M., Bowditch, W. A., Stevens, T., \& McLaren, I. P. L. (2014). The inhibitory control reflex. Neuropsychologia, 65, 263-278.

doi:http://dx.doi.org/10.1016/j.neuropsychologia.2014.08.014 


\section{INHIBITORY CONTROL TRAINING AND SMOKING}

Verbruggen, F., \& Logan, G. D. (2008a). Automatic and controlled response inhibition: Associative learning in the go/no-go and stop-signal paradigms. Journal of Experimental Psychology: General, 137(4), 649-672. doi:10.1037/a0013170

Verbruggen, F., \& Logan, G. D. (2008b). Response inhibition in the stop-signal paradigm. Trends in Cognitive Sciences, 12(11), 418-424. doi:10.1016/j.tics.2008.07.005

Verhaeghen, P., Marcoen, A., \& Goossens, L. (1993). 'Improving memory performance in the aged through mnemonic training: A meta-analytic study': Correction. Psychology and Aging, 8(3), 338-338. doi:10.1037/0882-7974.8.3.338

Wang, D., Connock, M., Fry-Smith, A., Moore, D., Barton, P., \& Aveyard, P. (2008). 'Cut down to quit' with nicotine replacement therapies in smoking cessation: A systematic review of effectiveness and economic analysis. Health Technology Assessment, 12(2), i-156. doi:10.3310/hta12020

West, R., Hajek, P., Stead, L., \& Stapleton, J. (2005). Outcome criteria in smoking cessation trials: proposal for a common standard. Addiction, 100(3), 299-303.

World Health Organisation. (2011).WHO report on the global tobacco epidemic. Retrieved from https://apps.who.int/iris/bitstream/handle/10665/70680/WHO_NMH_TFI_11.3_eng.pdf;jsessi onid=94844F67B0B295A43A0BB040F57A826E?sequence $=1$

World Health Organisation. (2015). WHO global report on trends in prevalence of tobacco smoking. Retrieved from http://apps.who.int/iris/bitstream/10665/156262/1/9789241564922_eng.pdf?ua=1: 


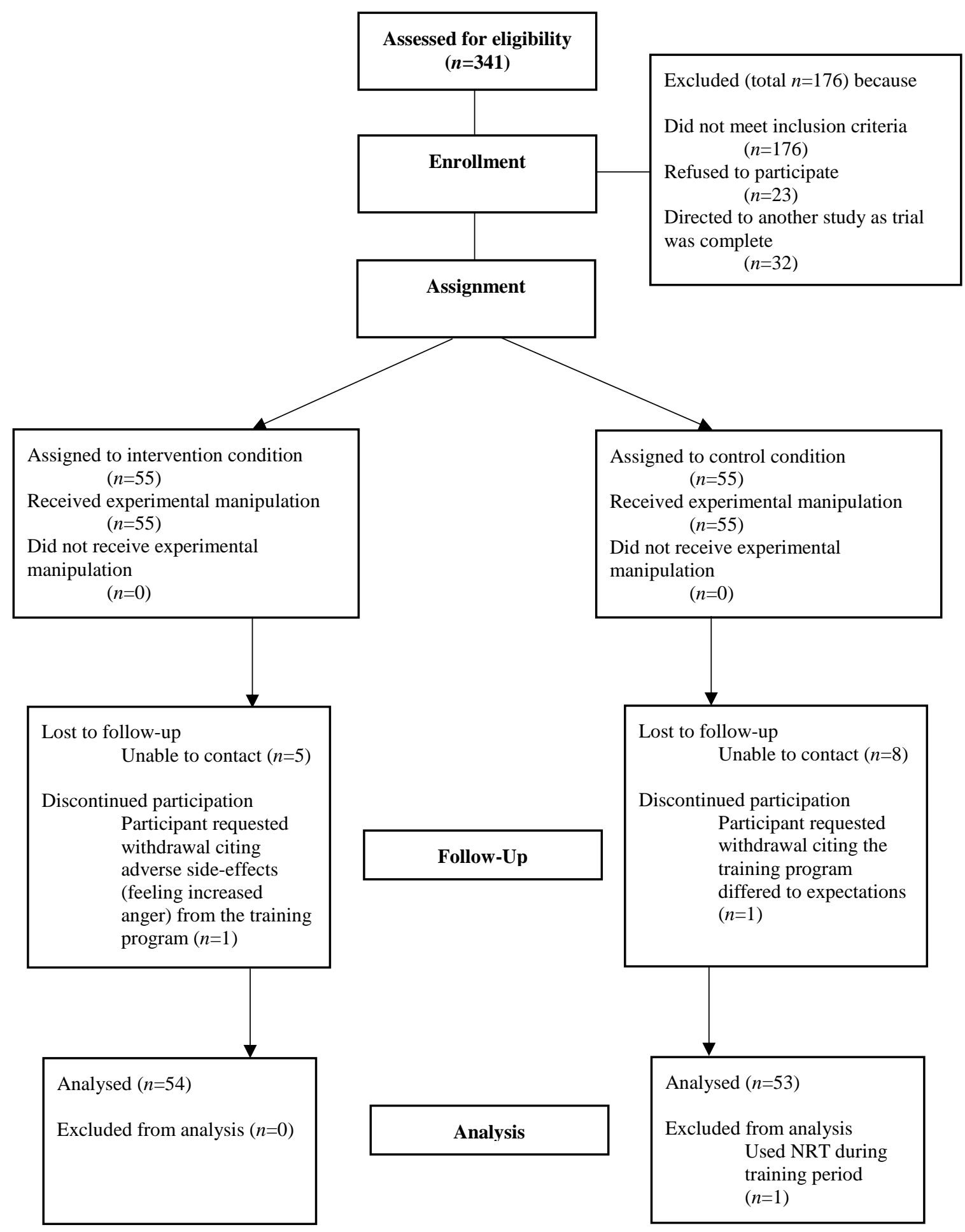

Figure 1. Recruitment flow diagram showing numbers of participants in each condition at each stage of the study. For details of participant screening, see Supplementary Table 1. 


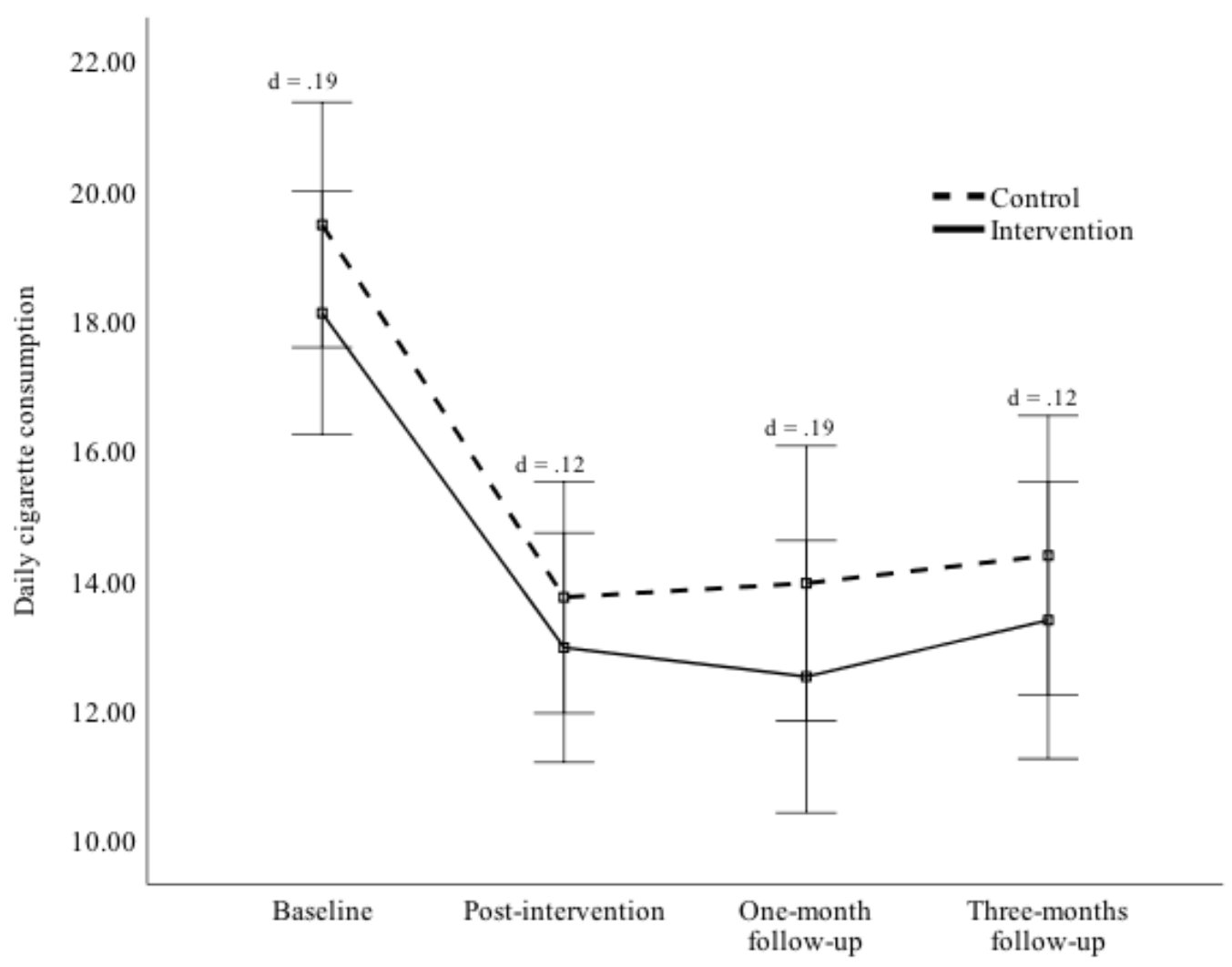

Figure 2. Daily cigarette consumption for each condition at baseline, post-intervention (T2), onemonth follow-up (T3) and three-months follow-up (T4). Values are means (bars are 95\% CIs). 


\section{INHIBITORY CONTROL TRAINING AND SMOKING}

Table 1

Demographic and Questionnaire Variables at Baseline

\begin{tabular}{lcc}
\hline & Control (SD) & Intervention (SD) \\
& $(n=53)$ & $(n=54)$ \\
\hline Age & $46.09(9.10)$ & $46.20(9.73)$ \\
Gender (\%F) & 50.94 & 55.55 \\
Tertiary educated (\%Y) & 62.26 & 70.37 \\
Employed (\%Y) & 79.25 & 81.48 \\
Cigarette consumption per day & $19.48(6.74)$ & $18.12(7.12)$ \\
Age commenced smoking & $15.75(2.43)$ & $16.69(2.41)$ \\
FTND & $5.72(2.02)$ & $5.41(1.80)$ \\
DSM-5 Tobacco Use Disorder symptoms & $6.57(1.86)$ & $6.59(2.11)$ \\
SSRT (ms) & $260(48)$ & $264(63)$ \\
BIS attention & $16.51(3.01)$ & $15.85(2.90)$ \\
BIS motor & $22.51(3.72)$ & $22.09(3.67)$ \\
BIS non-planning & $24.40(4.37)$ & $24.39(4.70)$ \\
\hline
\end{tabular}

Note. $\mathrm{SD}=$ standard deviation; $\mathrm{F}=$ female $; \mathrm{Y}=$ yes $; \mathrm{FTND}=$ Fagerström Test of Nicotine Dependence; DSM-5 = Diagnostic and Statistical Manual of Mental Disorders, Fifth Edition; SSRT = stop signal reaction time; ms = milliseconds; BIS = Barratt Impulsiveness Scale.

Table 2

Mean Task Adherence and Performance Across the Training Period

\begin{tabular}{lccc}
\hline & Control (SD) & Intervention (SD) & $\mathrm{F} / p$ \\
\hline ICT sessions completed & $10.89(3.20)$ & $10.50(2.91)$ & $.43 / .51$ \\
Go RT (ms) & $516(66)$ & $547(91)$ & $4.09 / .05$ \\
Go accuracy (\%) & $.99(.13)$ & $.98(.24)$ & $2.71 / .10$ \\
No-Go accuracy $(\%)$ & $.97(.02)$ & $.97(.02)$ & $.20 / .66$ \\
\hline
\end{tabular}

Note. $\mathrm{SD}=$ standard deviation; $\mathrm{ICT}=$ inhibitory control training; $\mathrm{ms}=$ milliseconds; $\mathrm{RT}=$ reaction time. 


\section{INHIBITORY CONTROL TRAINING AND SMOKING}

Table 3

Number of Participants Reporting Percent Days Abstinent at Post-intervention and One-and-ThreeMonths Follow-Up

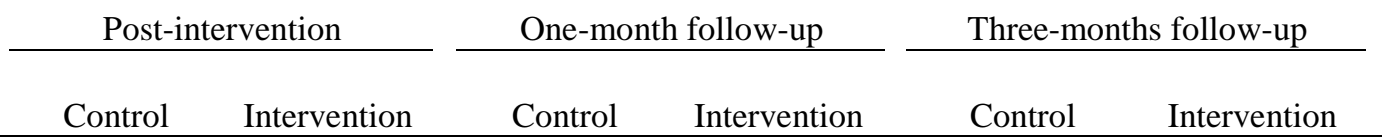

$\%$ Days abstinent

$\begin{array}{rrrrrrr}0 \% & 49 & 43 & 47 & 43 & 47 & 42 \\ 1-49 \% & 3 & 10 & 4 & 3 & 3 & 6 \\ 50-99 \% & 1 & 1 & 2 & 5 & 2 & 2 \\ 100 \% & 0 & 0 & 0 & 3 & 1 & 4\end{array}$

$\begin{array}{lllllll}\text { Cigarettes per day (SD) } & 13.75(7.10) & 12.97(5.95) & 13.96(7.29) & 12.53(8.19) & 14.39(7.60) & 13.39(8.18)\end{array}$

Table 4

Moderating Effect of Impulsivity on the Relationship between Condition and Cigarette Consumption

\begin{tabular}{|c|c|c|c|c|c|c|c|c|c|}
\hline & \multicolumn{3}{|c|}{ Post-intervention } & \multicolumn{3}{|c|}{ One-month follow-up } & \multicolumn{3}{|c|}{ Three-months follow-up } \\
\hline & $b$ & se & $95 \% C I$ & $b$ & se & $95 \% C I$ & $b$ & se & $95 \% C I$ \\
\hline $\begin{array}{c}\text { Condition x SSRT } \\
\text { (Analysis } 1)\end{array}$ & .01 & .02 & {$[-0.03,0.04]$} & -.01 & .02 & {$[-0.05,0.03]$} & -.02 & .02 & {$[-0.07,0.03]$} \\
\hline $\begin{array}{l}\text { Condition x BIS-A } \\
\text { (Analysis 2) }\end{array}$ & -.39 & .27 & {$[-0.92,0.15]$} & -.56 & .38 & {$[-1.31,0.20]$} & -.70 & .42 & {$[-1.53,0.12]$} \\
\hline $\begin{array}{c}\text { Condition x BIS-M } \\
\text { (Analysis 3) }\end{array}$ & -.12 & .22 & {$[-0.56,0.32]$} & .09 & .31 & {$[-0.52,0.70]$} & -.26 & .34 & {$[-0.93,0.41]$} \\
\hline $\begin{array}{c}\text { Condition x BIS-NP } \\
\text { (Analysis } 4)\end{array}$ & .03 & .18 & {$[-0.33,0.38]$} & -.16 & .25 & {$[-0.65,0.34]$} & -.18 & .28 & {$[-0.73,0.36]$} \\
\hline
\end{tabular}

Note. SSRT = stop signal reaction time; BIS-A = Barratt Impulsiveness Scale - Attentional; BIS-M = Barratt

Impulsiveness Scale - Motor; BIS-NP = Barratt Impulsiveness Scale - Non-Planning. 


\section{Supplementary Material}

\section{Supplementary Methods}

Participant screening. We received a total of 994 expressions of interest. Three-hundred and fortyone individuals were screened for eligibility and 176 individuals were excluded from participating in the present study, as they did not meet the eligibility criteria (see Table 1). Recruitment took placement between $22^{\text {nd }}$ February and $22^{\text {nd }}$ December 2017 (see Clinical Trials Registry: ACTRN12617000252314).

Table 1

Number of Ineligible Individuals for Each Inclusion/Exclusion Criterion

\begin{tabular}{|c|c|}
\hline Inclusion/Exclusion Criteria & $n$ \\
\hline Was not aged between $18-60$ years-old & 7 \\
\hline Smoked less than 10 cigarettes per day for the past 12 months & 24 \\
\hline Did not meet criteria for a moderate Tobacco Use Disorder as per the DSM-5 & 23 \\
\hline Was not motivated to make a quit attempt in near future & 3 \\
\hline Did not complete at least Year 9 (or equivalent) of schooling & 2 \\
\hline Did not have daily access to a computer and internet & 4 \\
\hline Primarily used electronic cigarettes & 6 \\
\hline Reported a period of abstinence for more than two-weeks over the past three months & 16 \\
\hline Used anti-craving medication & 3 \\
\hline Would not cease NRT during the training phase of the intervention & 4 \\
\hline Self-reported problematic AOD use & 38 \\
\hline Self-reported ABI, or LOC for more than 30 minutes & 12 \\
\hline Self-reported use of psychotropic medications & 71 \\
\hline
\end{tabular}

Notes. $n=$ number of individuals; DSM-5 = Diagnostic and Statistical Manual of Mental Disorders, Fifth Edition; NRT $=$ nicotine replacement therapy; $\mathrm{AOD}=$ alcohol and other drug; $\mathrm{ABI}=$ acquired brain injury; $\mathrm{LOC}=$ loss of consciousness. The sum of ineligible individuals per criterion $(n=213)$ is greater than the total number of ineligible individuals $(n=176)$ as some were excluded based on more than 1 criterion. 


\section{Supplementary Results}

Statistical analysis of inhibitory control training performance over time for the smoking-specific

training condition. Repeated measures ANOVAs were conducted to examine stimulus-specific learning effects (100\% stimuli vs. $50 \%$ stimuli) over time (first vs. fourth training session) as per Lawrence et al. (2015; see Table 2). Results indicated that accuracy significantly improved over time $\left(F(1,52)=17.29, p<.001, \eta_{p}{ }^{2}=.25\right)$ and there was a main effect of stimulus $(F(1,52)=16.73, p<$ $.001, \eta_{p}{ }^{2}=.24$ ), with greater accuracy towards the $100 \%$ No-Go stimuli (i.e., smoking) compared with the $50 \%$ No-Go stimuli (i.e., neutral). However, there was no stimulus $\mathrm{x}$ time interaction $(F(1,52)=$ $\left.2.47, p=.12, \eta_{p}{ }^{2}=.05\right)$. For reaction time, analyses indicated that reaction time decreased over time $\left(F(1,52)=6.43, p=.014, \eta_{p}^{2}=.11\right)$, however; there was no main effect of stimulus $(F(1,52)=1.04$, $\left.p=.312, \eta_{p}^{2}=.02\right)$ or time $\mathrm{x}$ stimulus interaction $\left(F(1,52)=4.00, p=.051, \eta_{p}^{2}=.07\right)$.

Table 2

Mean Go Reaction Time and Mean No-Go Accuracy at ICT Session 1 and 4

\begin{tabular}{lcc}
\hline & ICT Session 1 (SD) & ICT Session 4 (SD) \\
\hline Go reaction time ms (N) & $599(109)$ & $552(142)$ \\
Go reaction time ms (R) & $600(105)$ & $.97(.03)$ \\
No-Go Accuracy (N) & $.95(.04)$ & $.98(.03)$ \\
No-Go Accuracy (S) & $.98(.03)$ &
\end{tabular}

Note. $\mathrm{ms}=$ milliseconds; $\mathrm{N}=$ neutral stimuli; $\mathrm{R}=$ relaxing stimuli $; \mathrm{S}=$ smoking stimuli; $\mathrm{ICT}=$ inhibitory control training.

\section{Exploratory Analyses}

Table 3

Moderating effect of Dose and Gender on the Relationship between Condition and Cigarette Consumption

\begin{tabular}{|c|c|c|c|c|c|c|c|c|c|}
\hline & \multicolumn{3}{|c|}{ Post-intervention } & \multicolumn{3}{|c|}{ One-month follow-up } & \multicolumn{3}{|c|}{ Three-months follow-up } \\
\hline & $b$ & se & $95 \% C I$ & $b$ & se & $95 \% C I$ & $b$ & se & $95 \% C I$ \\
\hline Condition $x$ Dose & .29 & .27 & {$[-0.24,0.81]$} & .50 & .37 & {$[-0.23,1.24]$} & .35 & .41 & {$[-0.46,1.16]$} \\
\hline
\end{tabular}


INHIBITORY CONTROL TRAINING AND SMOKING

\begin{tabular}{cccccccccc} 
Condition x Gender & .15 & 1.69 & {$[-3.19,3.49]$} & 3.40 & 2.32 & {$[-1.21,8.00]$} & 3.13 & 2.55 & {$[-1.93,8.19]$} \\
\hline Table 4
\end{tabular}

Moderating Effect of Age on the Relationship between Condition and Cigarette Consumption

\begin{tabular}{|c|c|c|c|c|c|c|c|c|c|}
\hline & \multicolumn{3}{|c|}{ Post-intervention } & \multicolumn{3}{|c|}{ One-month follow-up } & \multicolumn{3}{|c|}{ Three-months follow-up } \\
\hline & $b$ & se & $95 \% C I$ & $b$ & se & $95 \% C I$ & $b$ & se & $95 \% C I$ \\
\hline Constant & -.39 & 1.13 & {$[-2.64,1.86]$} & -.84 & 1.53 & {$[-3.87,2.19]$} & 1.09 & 1.69 & {$[-2.27,4.44]$} \\
\hline Condition & .21 & .78 & {$[-1.34,1.76]$} & -.44 & 1.05 & {$[-2.53,1.65]$} & -.09 & 1.17 & {$[-2.40,2.23]$} \\
\hline Age & .06 & .04 & {$[-0.02,0.14]$} & $.17^{* *}$ & .06 & {$[0.02,0.14]$} & $.15^{*}$ & .06 & {$[0.03,0.27]$} \\
\hline Condition $\mathrm{x}$ Age & $.19^{*^{+}}$ & .08 & {$[0.03,0.36]$} & $.27^{*+}$ & .11 & {$[0.05,0.49]$} & $.33^{* *^{+}}$ & .12 & {$[0.09,0.58]$} \\
\hline Baseline Smoking & $.73 * * *$ & .06 & {$[0.62,0.84]$} & $.75 * * *$ & .08 & {$[0.60,0.90]$} & $.68 * * *$ & .08 & {$[0.51,0.85]$} \\
\hline \multicolumn{10}{|c|}{ Note. Condition x Age interaction at post-intervention $\left(\mathrm{F}_{\text {change }}=5.23, p=.024, \mathrm{R}^{2}\right.$ change $\left.=.02\right)$, one-month follow-up ( $\mathrm{F}_{\text {chang }}$} \\
\hline \multicolumn{10}{|c|}{$\begin{array}{l}{ }^{+} \text {After adjusting for multiple comparisons using the Bonferroni method the Condition } \mathrm{x} \text { Age interaction is no longe } \\
\text { statistically significant ( } 9 \text { comparisons, } \alpha=.006 \text { ). }\end{array}$} \\
\hline \multicolumn{10}{|l|}{$* p<.05$} \\
\hline \multicolumn{10}{|l|}{$* * p<.01$} \\
\hline$* p<.001$ & & & & & & & & & \\
\hline
\end{tabular}

Figure 3 presents the moderation effects using the JN technique. After adjusting for cigarette smoking at baseline, participants in the intervention condition were found to have significantly lower cigarette consumption when compared to the control condition at T2, T3 and T4 but only for participants aged below 24.83 years (T2), 36.88 years (T3) and 36.44 years (T4). Notably, at T2 and T4, participants in the intervention condition were found to have higher cigarette consumption when compared to the control condition, but only for participants aged above 58.37 years (T2) and 56.95 years (T4). 

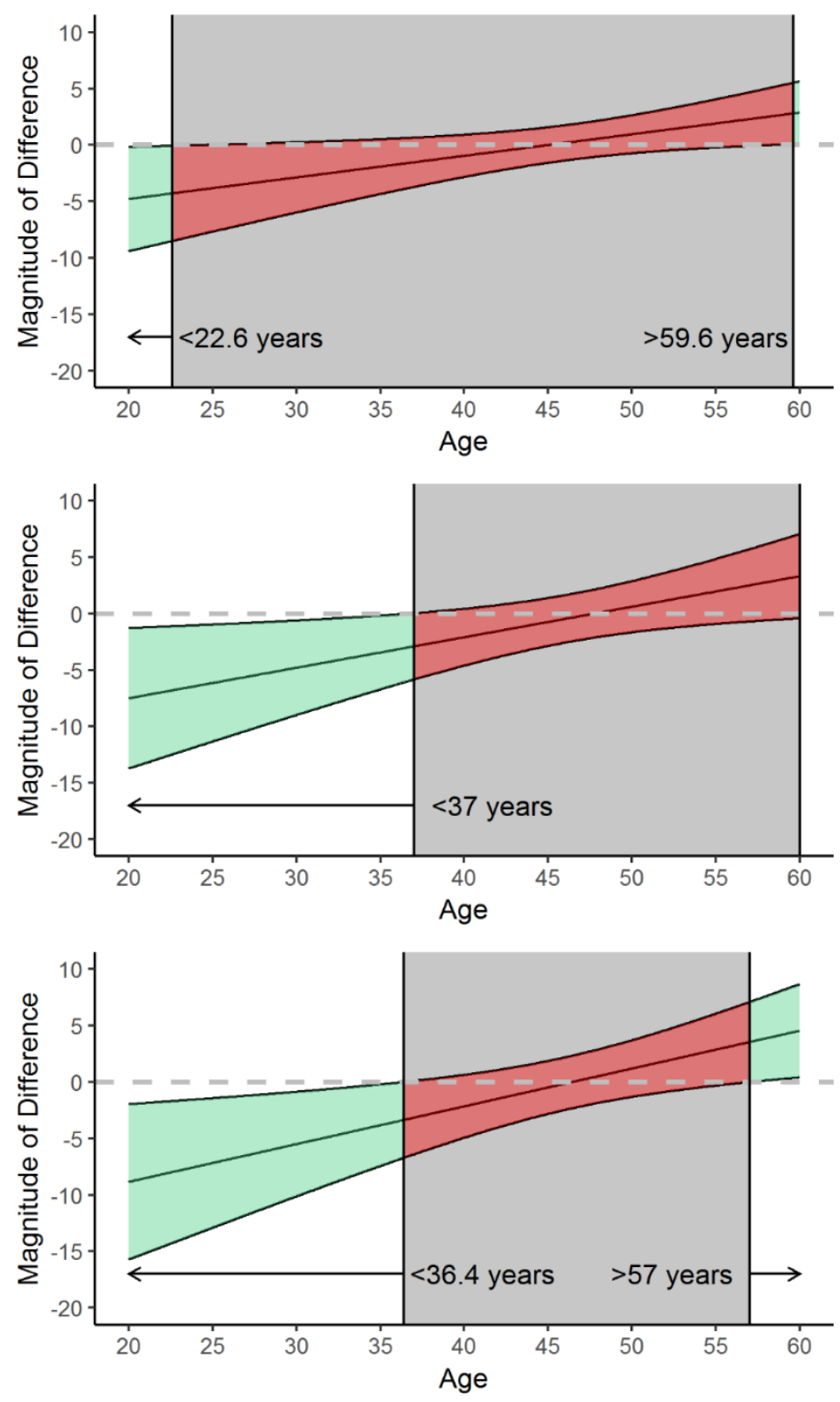

Figure 1. Johnson-Neyman figures representing the age x condition moderation effects for postintervention (top), one-month follow-up (middle), and three-months follow-up (bottom). Horizontal lines represent the expected difference in cigarette smoking (and associated 95\% CI) between conditions at each time point, after adjusting for baseline cigarette smoking. The green regions represent the ages at which the magnitude of the difference in daily cigarette smoking between conditions was different from zero (i.e., 95\% CI does not pass zero; specific ages are presented in each figure). A value below $y=0$ indicates greater reduction in the cue-specific condition (relative to the control condition) at the timepoint. Grey shaded area represent the ages at which there was no difference between the two conditions in reported cigarette consumption at the specific timepoint. 


\section{INHIBITORY CONTROL TRAINING AND SMOKING}

Given the apparent negative consequences of the intervention on cigarette consumption for individuals older than 58 years (T2) and 56 years (T4), we conducted follow-up examinations of participants over 56-years. Notably, given our sample recruited participants between 18 and 60-years, our sample comprised of only 20 participants over this age ( 18\%). On examination, one participant in the control condition reported a major decrease in cigarette consumption across all three timepoints, which we believe was driving the result towards more improvement in the control condition. When this participant was removed, there was no longer a difference between conditions at T2 and T4 for older participants (see Figure 2). We also repeated these analyses controlling for nicotine dependence (FTND). The condition $\mathrm{x}$ age interaction was robust to covariate adjustment at T2 (t(101) $=2.70, p=.008,95 \% \mathrm{CI} .06-0.40), \mathrm{T} 3(t(101)=3.14, p=.002,95 \% \mathrm{CI} .13-0.57)$ and $\mathrm{T} 4(t(101)=$ $3.25, p<.001,95 \%$ CI $.16-.65)$.
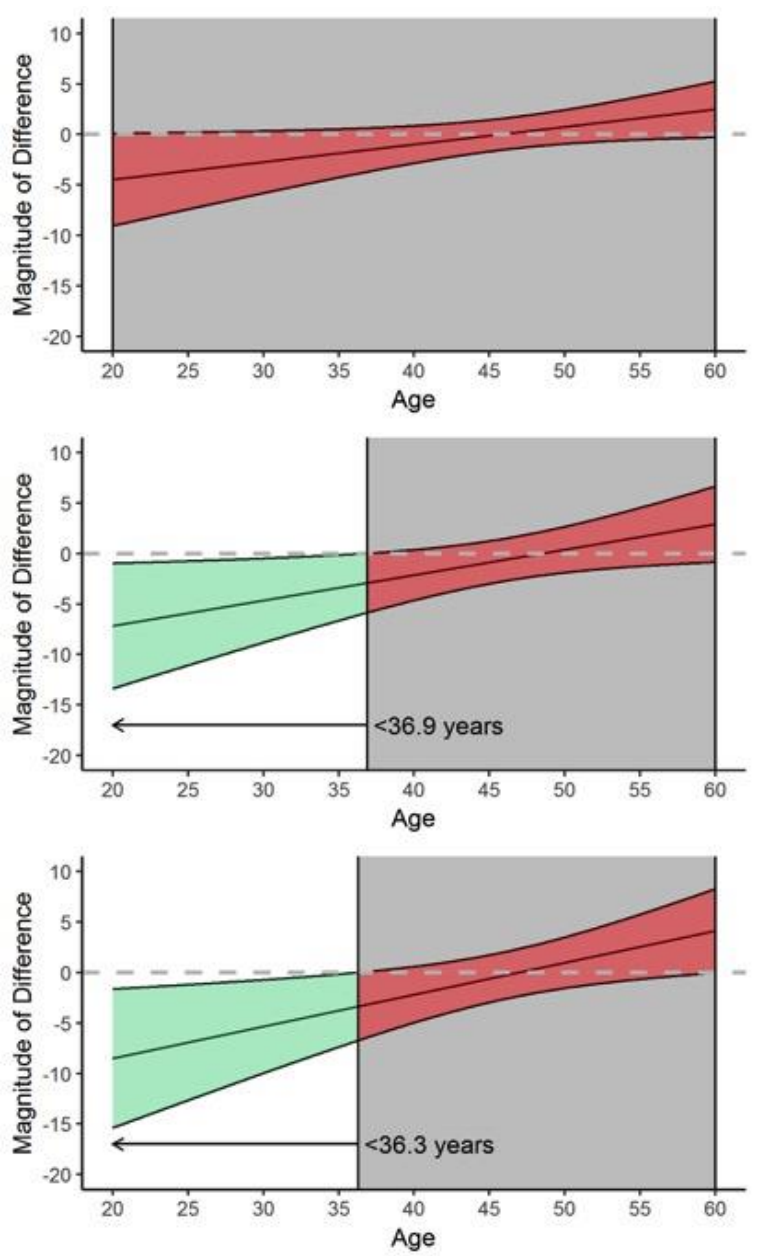


\section{INHIBITORY CONTROL TRAINING AND SMOKING}

Figure 2. Johnson-Neyman (JN) figures representing the age $\mathrm{x}$ condition moderation effects for postintervention (T2; top), one-month follow-up (T3; middle), and three-months follow-up (T4; bottom) with one participant removed $(\mathrm{N}=106)$. Horizontal lines represent the expected difference in cigarette smoking (and associated 95\% CI) between conditions at each follow-up point, after adjusting for baseline cigarette smoking. The green regions represent the ages at which the magnitude of the difference in daily cigarette smoking between conditions was different from zero (i.e., 95\% CI does not pass zero; specific ages are presented in each figure). A value below $y=0$ indicates greater reduction in the smoking-specific condition (relative to the control condition) at the timepoint. Grey shaded areas represent the ages at which there was no difference between the two conditions in reported cigarette consumption at the specific timepoint.

\section{Supplementary Discussion}

Exploratory moderator analyses provide some weak evidence suggesting that smoking-specific ICT may be effective at reducing daily cigarette consumption for younger participants only; however, we recommend caution drawing inferences from this finding as the effect was no longer statistically significant after adjustment for multiple comparisons error using the Bonferroni procedure. Nonetheless, if future research is able to find evidence that smoking-related ICT is particularly effective at helping younger adults reduce cigarette consumption, it may have important clinical implications. Specifically, reductions in daily cigarette consumption have been shown to yield considerable long-term health benefits (Eliasson, Hjalmarson, Kruse, Landfeldt, \& Westin, 2001; Gerber, Myers, \& Goldbourt, 2012; Lee, 2013; Lotan, Goldbourt, \& Gerber, 2017) and importantly, can lead to improved cessation outcomes (Asfar, Ebbert, Klesges, \& Relyea, 2011; Ebbert, Hughes, \& West, 2015; Hughes \& Carpenter, 2006; Klemperer \& Hughes, 2015; Wang et al., 2008). Therefore, smoking-related ICT may be a promising approach for this sub-group of the population to reduce consumption, which may assist in achieving complete cessation.

In addition, an exploration into the underlying mechanisms of this age-related finding may be warranted. One potential explanation may be that younger adults have increased neuroplasticity, and 


\section{INHIBITORY CONTROL TRAINING AND SMOKING}

therefore, show greater benefits from cognitive training compared to older adults (Brehmer, Westerberg, \& Bäckman, 2012; Calero \& Navarro, 2007; Dahlin, Nyberg, Bäckman, \& Neely, 2008; Verhaeghen, Marcoen, \& Goossens, 1993). For instance, a series of reviews indicate that cognitive training can lead to greater improvements for younger compared to older adults, and, that younger adults are able to maintain the effects of training over time to a greater extent compared to older adults (Joness et al., 2006; Lillard \& Erisir, 2011; Lustig, Shah, Seidler, \& Reuter-Lorenz, 2009; Noack, Lövdén, Schmiedek, \& Lindenberger, 2009; Park \& Bischof, 2013). Similarly, parallel literature across executive functions has demonstrated that there are age-related differences in associative learning (Clark, Hazeltine, Freedberg, \& Voss, 2018; Kray \& Eppinger, 2006) and therefore, younger adults may have been able to form cue-inhibition associations more effectively than older adults. Finally, it is possible that older smokers, who have smoked for a longer period of time and may have more entrenched habits are less sensitive to devaluation of cigarette cues than younger smokers. This idea is potentially consistent with prominent theories of addiction such as the habit-formation theory (Everitt \& Robbins, 2005) that suggest that repeated and long-term use of addictive substances leads to a shift in behaviour from being goal-oriented (and sensitive to reinforcer devaluation) to habitual (insensitive to reinforcer devaluation). However, our interaction was robust to covariate adjustment of nicotine dependence and therefore, further investigation into the underlying mechanisms of ICT may shed light on its potential differential effectiveness by age. 